\title{
Endogenous and exogenous problems in children of addicted mothers
}

\author{
Lombard S, J-F*, Swabey K and Pullen D \\ Faculty of Education, University of Tasmania, Australia
}

\begin{abstract}
Maternal addiction is a significant factor behind the endogenous and the exogenous problems in children. This study extends the works of Cicchetti and Rizley (1981) by providing developmental parameters to classify, categorize and identify common and salient problems of children of addicted mothers (COAM). An archival method was used to review files (36 files, 69 participants, male=39 and female=30) from a residential drug rehabilitation facility. Files were reviewed in terms of children's health and psychological problems and the purpose of the study was to discover how maternal addiction negatively influences children in relation to specific drugs; and to determine the severity and the nature of those problems in terms of how maternal addiction translates to particular problems in children. Results showed that common endogenous problems ranged from biological to psychological problems, with cognitive deficits and emotional wellbeing being salient problems. In terms of exogenous problems, unstable home environments, neglect and abuse were salient. A novel finding of this study was the occurrence of enuresis and encopresis for children, up to the age of 17 . Implications of the study are discussed.
\end{abstract}

\section{Introduction}

The proposed study extends the work of Cicchetti and Rizley (1981) [1] by providing developmental parameters to classify and categorize endogenous problems (i.e., problems that are inherent in the child as a result of a mother's addiction) and exogenous problems (i.e., problems as a result of or due to external factors) for children of addicted mothers (COAM). Generally, previous studies have done very little to systematically categorize problems from a developmental paradigm, making it difficult to assess the type of and severity of problems in terms of whether it is mild, moderate or severe within a developmental context [2-4]. While an extensive effort has been invested in capturing children's endogenous and exogenous problems as a result of their mother's addiction, it has occurred in an ad hoc manner. Hence, little is known if there are salient and/or common problems in terms of severity with respect to mother's primary addiction. Without a framework to accurately capture and classify endogenous and exogenous problems, it is difficult to assess the kind of negative experiences children are likely to have and how best to support them not only within a schooling context but also in their everyday lives. Thus, the need for the current study was due to two important reasons. First, the lack of any parameters to classify and categorize endogenous and exogenous problems of COAM. Second, there is a lack of holistic baseline information on children's problems.

There is a need to better understand the problems of COAM in order to provide timely and ongoing holistic care, as support for COAM usually appears to be ad hoc $[5,6]$. Thus, a baseline holistic data in terms of how maternal addiction impacts upon COAM is urgently needed, and while some critics may argue that addiction is a personal and private matter, it becomes a serious concern when it has negative affects COAM. Thus, classifying, categorizing and identifying problems faced by COAM would better inform clinicians, teachers, principals, and schools in how best to support these children and they would be better equipped to provide COAM with targeted services, referrals to specialists, and/or special services to cater for the various problems [7-10].
In Australia, it is estimated that $13 \%$ of children under the age of 14 are living with a drug-addicted parent [11]. Maternal addiction has been identified as a significant factor for endogenous and exogenous problems in children $[12,13]$. Studies have identified that drug addiction significantly impacts a mother's ability to parent and to be a responsible caregiver. Furthermore, drug addiction greatly limits and obscures a mother's capacity to appropriately identify, recognize and respond to their children's problems; in seeking support; and as well as underreporting problems [10,14-16]. Being exposed to the culture of drugs COAM are susceptible to negative experiences (e.g. Malnourished) and undesirable environments (e.g. Unsafe and/or unstable home) which are not conducive to their development. This is further compounded by multiple risk factors at various levels: i.e., social and psychological difficulties, which make it difficult to accurately locate and catalog this problem/s [10-20]. Thus, having a framework to classify, categorize and identify these problems is urgently needed.

In terms of endogenous problems of children, whose mothers are addicted to legal drugs (i.e. alcohol); the most salient problem is foetal alcohol syndrome disorder (FASD) [21]. FASD is the direct result of alcohol's teratogenic effects during pregnancy resulting in a pattern of birth defects from the disruption of normal development to neonatal development $[17,19,22]$. Other studies have found that maternal alcohol addiction correlates with several endogenous problems such as externalizing violent behaviors and internalizing mental health problems. Children of alcohol addicted parents are more likely to be victims of abuse or neglect and are more likely to witness

Correspondence to: Dr. J-F, Lecturer, Faculty of Education, University of Tasmania, Locked Bag 1304, LAUNCESTON TAS -7250, Australia, Tel: +61 3 6324 3166, Fax: 6136324 3048, E-mail: j.f@utas.edu.au

Key words: drugs, children, psychological problems, and maternal addiction

Received: April 02, 2017; Accepted: April 21, 2017; Published: April 23, 2017 
violent behavior and suffer emotional/psychological harm due to the inconsistencies in parental attention, supervision, and affection [2325]. It is very difficult to fully grasp and capture exogenous problems primarily because alcohol is easily available to most adults (e.g., 18+) and alcohol is used in numerous social contexts and environments $[9,11,26]$. However, studies found several exogenous problems such as: unsafe environments for children to grow and develop [6,20,23,24,2729]. Thus, accounting problems for COAM provides a systematic insight into the kinds of problems and their severity.

In terms of endogenous problems of children, whose mothers are addicted to illicit illegal drugs such as heroin and amphetamines - it has been found that children have significant physical and cognitive problems [22,30-32]. In one study, children around the age of five, of heroin-addicted mothers, were found to have scored significantly lower on verbal, motor, memory and general cognition compared to the general population [4]. In another study, a significant indicator of behavioral and post-natal cognitive problems in children was from mothers addicted to heroin [2]. A unique finding of 30 was that in some cases, children of addicted mothers to heroin were given up for adoption, but it is unclear whether this is related to heroin addiction in particular, or whether this primarily related to environmental deprivation in general (e.g. Transient, regularly moving from house to house) and unstable lifestyle as a result of being addicted to drugs in general. Amphetamines decrease the gestational period, with $29.5 \%$ of mothers delivering preterm, putting the life of the child at a higher likelihood of needing additional medical support [31]. Other studies on maternal amphetamine addiction have found a combination of problems, for example; congenital defects, cardiovascular abnormalities, musculoskeletal abnormalities, cognitive problems, oppositional defiant disorder and attention deficit hyperactivity disorder [22]. In terms of exogenous problems, a child's micro and macro social environment have been found to be very negative, for example, inconsistent school attendance, temporary routines, limited access to health care and unhealthy family relationship [2,6,24,32,33]. Again, systematically, capturing the problems of COAM is likely to provide critical insights into the kinds of problems and their severity with respect to particular drugs.

In terms of endogenous problems for children, whose mothers are addicted illicit pharmaceutical, very little is known in terms of how illicit pharmaceutical accounts for endogenous and exogenous problems in children. However, having concurrent information as to the children's social and emotional problems alongside biological and physical problems with regard to legal, illicit illegal and illicit pharmaceutical would also greatly assist in knowing the kinds of problems associated with maternal drug addiction.

\section{Context of the study}

The current study reviewed archival intake files from a drug rehabilitation facility for mothers with children. These intake files were reviewed to classify, categorize and identify common and salient - endogenous and the exogenous problems for COAM from a developmental paradigm. Consequently, COAM problems were mapped against four developmental domains (social, emotional, cognitive and physical) as these provide normative baseline indicators for lifespan development [34].

\section{Ethics}

This study meets ethical guidelines in terms of informed consent, ethical approval, and including adherence to the legal requirements of
Australia, as it was considered and approved the Tasmanian Health and Medical Human Research Ethics Committee (Ref No: H0015080). All aspects of the study: obtaining consent, data collection, analysis, and dissemination are in line with the Health and Medical HREC (Human Research Ethics Committee, University of Tasmania) and comply with the National Statement on the Ethical Conduct in Human Research (NHMRC 2007 updated 2014).

\section{Research aims}

1. Capture how maternal addiction impacts (i.e., negative) children in relation to specific drugs.

2. Appreciate both the severity and nature of these problems in terms of how maternal addiction translates to problems in children.

\section{Method}

\section{Participants}

Archived files from 2005 to 2011 were reviewed by the Research Team (i.e., a developmental specialist, a health specialist, and a research assistant with four years' experience of working in child development); and each file was examined to locate, classify, categorize and identify common and salient - endogenous and the exogenous problems. Of the114 files of mothers with a total of 177 children, 78 files were excluded as they had missing information; consequently this study reviewed only 36 files of mothers with a total of 69 (male $=39$, female $=30$ ) children, who ranged from birth (born in the center) to the age of 18 years, and only two children identified as Indigenous.

\section{Design}

All de-identified data with regard to children and their mothers from the archival files were forwarded by the CEO of the drug rehabilitation facility to the Research Team. These archival files were non-medical intake files from the drug residential rehabilitation facility at the time of admission into the center for treatment. At intake, mothers provided biographical details about themselves and their addiction and clinical/non-clinical information about their problems and their children's problems.

\section{Data collection}

Child related problems were extracted from the files in simple lay terms (e.g., bedwetting) and/or in clinical language (e.g., depressed) and irrespective of the terms or the language, all problems were extracted from the files along with the mother's primary drug addiction. Consequently, in line with the focus of the study, the following items were extracted from the archival files: age of the mother, primary and secondary drug addiction of the mother, age of the child, gender, number of siblings, birth order, grade, child related problems reported by their mothers at the time of intake, mother's age, and importantly, any and all recorded information in terms of symptomologies, concerns and problems with regard children.

\section{Data coding}

Information with regard to children's symptomologies, concerns and problems noted in the archival files were not thematically or clinically coded. This was done to safeguard the integrity of the data and to limit confounds. For example, if a file note stated that "... the child appeared cognitively delayed..." it was simply reported as the same and equally where a file note read “...cognitive impairment..." irrespective of whether it was based on an objective cognitive assessment or not, 
it was simply recorded as cognitive impairment. Similarly, reports of sexual abuse of a child were not based on any official documentation or from any particular child protection agency; if it was recorded in the archival file it was reported as such. Australian Institute Health and Welfare [AIHW] (2013) drug cataloging system was used to classify drugs as legal (e.g. Alcohol and tobacco), Illicit Illegal (e.g., heroin and cocaine) and Illicit Pharmaceutical (e.g. Methadone - used without a clinical reason and when self-prescribing).

\section{Data analysis}

Both data of mothers and children were mapped against the four developmental domains (social, emotional, cognitive and physical) and endogenous and exogenous children's problems. The four developmental domains are four faculties that help map progress of development with respect to chronological age and stages of life (e.g., infancy, early childhood, middle childhood, adolescence, and adulthood) [34]. Data (i.e., symptomologies, concerns, and problems) were analyzed in terms of endogenous and exogenous children's problems [35]. Further, data were mapped against the severity of the problems (mild, moderate, and severe) to appreciate to what extent children were reported to be affected and this classification was per the Diagnostic Statistical Manual for Mental Disorders (DSM) IV (1994) [36]. Data also was plotted against Multiaxial Assessment in terms of DSM IV (1994) with regards to endogenous and exogenous problems or symptomologies as descriptive behaviors for various disorders. It is appropriate to use Multiaxial Assessment as per DSM IV (1994) to show the various endogenous and exogenous problems mapped against AXIS I, II, III, and AXIS VI as it provides a holistic understanding of the kinds of problems reported and to show the various diagnostic implications at the different levels of Multiaxial Assessment [36]. Consequently, data were charted against Multiaxial Assessment and results are presented in a descriptive manner. Consequently, this study used

Table 1. Age of children

\begin{tabular}{|l|c|c|c|}
\hline Age & Number of boys & Number of girls & Total Number of children \\
\hline $0 *-3$ & 18 & 13 & 31 \\
\hline $4-7$ & 12 & 10 & 22 \\
\hline $8-10$ & 6 & 4 & 10 \\
\hline $11-16$ & 3 & 1 & 4 \\
\hline $17+$ & 1 & 1 & 2 \\
\hline
\end{tabular}

$*_{0}$ indicate a birth in the center.
DSM-IV classification of AXIS I, II, III, while the Diagnostic Statistical Manual of Mental Disorders (DSM) V (2015) [37] has combined AXIS I, II, III, and has adopted AXIS VI to Other Conditions That May Be a Focus of Clinical Attention and has dropped the Global Assessment of Functioning (GAF) [38]. For the purpose of this study, addiction was operationalized in terms of mothers being addicts of a drug, given that they all sought treatment at a residential drug treatment facility.

\section{Results}

As shown in Table 1, a total of 32 children were of school age and enrolled in primary school (4-7 and 8-10), 6 children were enrolled in secondary school (11-16 and 17+) and 31 children were below school age. Over $55 \%(n=38)$ of children required some level of school- based support, while the other $45 \%$ required some kind of neonatal support. A total of 8 children were documented to be born premature, while 3 children were recorded to be born dependent on Heroin and 1 child was born dependent on Amphetamines (Table 1).

As indicated in Table 2 the majority of mothers were addicts of alcohol $(36 \%)$, followed by amphetamine $(22 \%)$, heroin $(11 \%)$ and speed (11\%). Children exposed to maternal alcohol addiction were less than half $(47 \%)$, followed by amphetamine $(24 \%)$, heroin $(5 \%)$ and speed (7\%). Children were primarily exposed to several risk factors and environments related to alcohol, amphetamine, heroin and speed. The most commonly reported problems were: maternal neglect, being social ineptitude and global cognitive and physical delays or problems. Interestingly, two children whose parents were addicts of heroin were high performing school students. Moreover, some notable findings were: a total of 11 children were documented to have enuresis and encopresis whose mothers were addicted to amphetamine and alcohol, and two children whose mothers were addicts of amphetamine were documented to be hurting animals. It was reported by mother's that children were victims of sexual abuse was a common problem for all children for all of the drug conditions (Table 3 ).

Almost all children of drug addicted mothers were found to have severe problems across all of the developmental domains (social, emotional, cognitive and physical), as shown in Tables 3 and below in 4. More specifically, the biggest concern was that a majority of children were cognitively delayed, followed by engaging in ODD-like behaviors, and then malnourishment. It is very likely that one child could be displaying a number of problems within each of the domains.

Table 2. Mothers primary drug addiction and children.

\begin{tabular}{|c|c|c|c|c|}
\hline \multirow[t]{2}{*}{ Primary Drug } & \multirow[t]{2}{*}{ No*. of Mothers } & \multirow[t]{2}{*}{ No*. of Children } & \multicolumn{2}{|l|}{$\begin{array}{l}\text { Child related salient problems } \\
\text { (No. of Children*) }\end{array}$} \\
\hline & & & Endogenous & Exogenous \\
\hline $\begin{array}{l}\text { Licit } \\
\text { Alcohol }\end{array}$ & 13 & $33 *$ & $\begin{array}{l}\text { Cognitively delayed (9*), Angry behavior (6), } \\
\text { Aggressive behavior (6), Language delays (3), } \\
\text { Communication delays (3), FAS (1), Low muscle } \\
\text { density (2), Enuresis and Encopresis (7). }\end{array}$ & $\begin{array}{l}\text { Poor performance (11), Sexually abused (4), Maternal } \\
\text { neglect (14). }\end{array}$ \\
\hline $\begin{array}{l}\text { Illicit/Illegal } \\
\text { Amphetamine }\end{array}$ & 8 & 16 & $\begin{array}{l}\text { Hurting animals (2), Premature (4), Malnourished (6), } \\
\text { Enuresis and Encopresis (4). }\end{array}$ & $\begin{array}{l}\text { Maternal neglect (13), No health care access (7), Sexually } \\
\text { abused (4), Socially inept (12). }\end{array}$ \\
\hline Heroin & 4 & 4 & Spatially inept (1), Cognitively delayed (2). & High performance (2), No siblings (4). \\
\hline Speed & 4 & 5 & Hypersensitive (2). & Socially isolated (3). \\
\hline Marijuana & 2 & 3 & Medical ill (2). & Disassociated disorder (2). \\
\hline Ice & 1 & 1 & Birth brain damage (1). & \\
\hline \multicolumn{5}{|c|}{ Illicit/Pharmaceutical } \\
\hline Benzo & 1 & 3 & Cognitively delayed (3). & Submissive (3). \\
\hline Methadone & 1 & 2 & & Manipulative (1). \\
\hline Pharmaceutical & 1 & 2 & Cognitively delayed (2). & Sexually abused (1). \\
\hline
\end{tabular}

*Represents cumulative problems with regard to a number of children displaying similar behaviors. For example, cognitively delayed (9), indicating that 9 children were found to have cognitive deficits. 
Table 3. Cumulative children's problems mapped against developmental domains.

\begin{tabular}{|c|c|c|c|c|}
\hline \multirow[t]{2}{*}{ Severity of the problem } & \multicolumn{4}{|c|}{ Nature of the Problem in terms of numbers } \\
\hline & $\begin{array}{l}\text { Social } \\
\text { (No*. of children) }\end{array}$ & $\begin{array}{l}\text { Emotional } \\
\text { (No*. of children) }\end{array}$ & $\begin{array}{l}\text { Cognitive } \\
\text { (No** of children) }\end{array}$ & $\begin{array}{l}\text { Physical } \\
\text { (No*. of children) }\end{array}$ \\
\hline Mild** & 0 & 0 & 0 & 0 \\
\hline Moderate** & Immature*** (5*), Awkward*** (6). & 0 & 0 & Under weight (20), Over weight (6) \\
\hline Severe** & $\begin{array}{l}\text { Anti-social (15), } \\
\text { ODD symptomologies (18), } \\
\text { Submissive (4), Dominating (6), } \\
\text { Promiscuous } \\
\text { (2). }\end{array}$ & $\begin{array}{l}\text { Insecure attachment (7), Depression } \\
\text { (3), Nervous by the presence of older } \\
\text { adult male } \\
\text { (2), ODD symptomologies (18), } \\
\text { Submissive (4), Suicidal (3), Poor self- } \\
\text { esteem (6), }\end{array}$ & $\begin{array}{l}\text { Non-verbal (3), Language delay } \\
\text { (9), Cognitively delayed (23), } \\
\text { Hypersensitive (3), Dissociative } \\
\text { disorder (3), Spatially inept (3). }\end{array}$ & $\begin{array}{l}\text { Sexual abuse (9), Enuresis and } \\
\text { Encopresis (11), Premature (8), Born } \\
\text { drug dependent (4), FAS (1), Brain } \\
\text { damage (1), } \\
\text { Malnourished (16), Chronic fatigue } \\
\text { (8), Poor muscle definition (3), } \\
\text { Medically ill (11). }\end{array}$ \\
\hline
\end{tabular}

*Represents cumulative problems with regard to a number of children displaying similar behaviors, For example, Immature (5), indicating that 5 children were found to be acting immature relative to their age.

**The operational definition for these are informed by DSM IV and DSM V.

*** Terminology (i.e., awkward, immature) reported in the case files was used as is, to not add or redact the original meaning.

Table 4. Salient problems on multiaxial assessment.

\begin{tabular}{|l|l|l|l|}
\hline Nature of problems & Multiaxial Assessment & Number of children & Salient problems (e.g., symptomologies and/or behaviors) \\
\hline Endogenous & Axis I & $43^{*}$ & $\begin{array}{l}\text { Anger (15*), Depression (3), Suicidal ideations (3), Disassociated disorder (3), Promiscuity (2), ODD } \\
\text { symptomologies (18), Expressive language disorder symptomologies (9), Sexual abuse (9), Chronic } \\
\text { fatigue (8), Medically ill (11), Neglect (27), Hypersensitive (3), Spatially inept (3), Poor self-esteem (6), } \\
\text { Conduct Disorder like behaviors (8) }\end{array}$ \\
\hline & Axis II & & $\begin{array}{l}\text { Enuresis (11), Heroin dependent child (3), Amphetamine dependent child (1), Premature birth (8), Brain } \\
\text { damage (1), FAS (1), Abnormally underweight (20), Abnormally overweight (6), }\end{array}$ \\
\hline & Axis III & 25 & $\begin{array}{l}\text { Transient lifestyle (12), Removal from the home (10), Inadequate discipline (14), Inadequate health care } \\
\text { (16), Antisocial symptomologies (15) }\end{array}$ \\
\hline Exogenous & Axis IV & $\begin{array}{l}\text { Most children were reported to be globally functioning below their developmental age. Delayed executive } \\
\text { functioning (23) }\end{array}$ \\
\hline & Axis V & & \\
\hline
\end{tabular}

*Represents cumulative problems with regard to a number of children displaying similar behaviors. For example, Anger (15), indicated 15 children were documented to display angry behaviors.

Table 4 shows the majority of salient problems on Multiaxial Assessment were behaviors and symptomologies indicative of meeting the certain criterion for psychological disorders as per DSM V (2015). For example, a majority of children were documented to have been neglected by their mothers, followed by delayed executive functioning, and then abnormally underweight and finally symptomologies were suggestive of Oppositional Defiant Disorder and reported of speaking to the devil.

\section{Discussion}

Findings from this study confirmed that COAM have a range of problems. These problems include language and communication deficits, gaps in cognitive processing, emotional instability, attention problems, highly challenging behavior, developmental delays, victims of sexual abuse and neglect, and a range of social problem ranging from being submissive to dominating or rebellious behaviors [10$13,15,16,18-20]$. An interesting finding from this study was that 108 out of 177 children had no recorded problems in their respective intake file. It is highly improbable that this amount of children did not have any problems reported, perhaps in a way it could be suggestive of mothers under-reporting their children's problems [10,14-16].

Importantly, the current study has found that almost all of the children had severe problems across all four developmental domains, to the extent that many of behaviors qualified and/or met several criteria of either a psychological disorder or a developmental delay. Further, several of the behaviors displayed by COAM directly corresponded to the criteria for clinical disorders in that most of the behaviors loaded onto Axis I and V of the Multiaxial Assessment. This is a serious concern showing that many of the COAM require a high level of support and intervention. Maternal addiction, irrespective of the drug, appears to have serious developmental implications for children in terms of developing psychological disorders and/or leading to developmental delays or both.

A novel finding of the current study was the presence of problems that resemble symptoms of enuresis (i.e., the repeated passing of urine in places other than the toilet, [38]) and encopresis (i.e., the repeated passing of faeces in places other than the toilet, [38]) in COAM up to 17 years of age of mothers addicted to alcohol and amphetamines. Future studies must closely investigate the occurrence of enuresis and encopresis and must account for these symptoms in terms of their etiology and the rate of occurrences as it may have implication for the children throughout the lifespan in terms of psychological and physiological problems. Even though this study found that all COAM to be victims of sexual abuse, wherein it was reported that more boys than girls were victims of abuse across all drug addictions both licit and illicit, but caution must be exercised in generalizing these findings as the sample was too small and had relatively more boys. Therefore, serious attention must be given to the safety of children if the mothers are addicts, as their children are at risk of being victims of sexual abuse. An unusual finding of the study was that it found two COAM to heroin to be high performers (i.e., cognitive domain) in education and more serious attention needs to be given these children. Future studies must investigate this and while this finding is not in line with the studies on heroin, consideration must be given to examining what high performance means in terms and knowing whether they add to any possible developmental gains for the children [2]. While one could argue that, a possible reason for this finding could be that these children are outliers, and others could equally, argue that this is 
indicative of intensive support and/or intervention [2]. Irrespective of the arguments, it is promising to learn that a child can make positive cognitive gains even while exposed to untoward incidences and perhaps appropriate, timely and much needed support can aid in terms of identification and in the setting up of an action plan to care.

In terms of endogenous and exogenous problems for COAM relating to legal drugs, i.e., alcohol, this study found that children of alcoholic mothers had a high occurrence of extremely aggressive behaviors, maternal neglect, high levels of poor performance, cognitive delays, and these findings are in line with previous studies [17,19-21,23,24,27-29]. It appears that COAM of alcohol seems to have mainly cognitive related concerns with regard to an inability to communicate (e.g., share their feelings openly and comfortably) and process language (e.g., difficulty in expressive and receptive faculties). This is perhaps due to mothers being negligent or being absent and not positively interacting with their own children. COAM need to be provided with opportunities to develop communication and language skills and to build positive relationships so that they experience a sense of community around them in all environments.

In terms of endogenous and exogenous problems for COAM relating to illicit drugs, this study has confirmed the findings in relation to cognitive, social and physical delays, and exposure to environmental risk factors such as maternal neglect $[2,4,21,22]$. In addition, this study also found that many COAM engaged in extreme behaviors, such as hurting animals and destruction of property. Importantly, it was reported that one child was speaking to the devil, which perhaps could be indicative of early signs of psychosis, but to what extend this is accurate needs to be further examined. Thus, future studies must closely investigate at what age children are likely to develop signs of psychosis. And, in terms of endogenous and exogenous problems for COAM relating to illicit and/or use pharmaceuticals, all experienced cognitive delays relative to their peers. Future studies must use the findings from this study as a baseline to more critically examine the kinds of problems COAM have, wherein future studies must study to what extent there is a correlation between primary drug of choice and the child related problems. Knowing this information can lead to the development of drug specific targeted programs to help children and mothers.

\section{Implications for practice}

In terms of implications, proactive steps must be taken by clinicians, teachers, principals, schools, and rehabilitation facilities to provide a safe place for COAM and set up systematic, multilayered support opportunities to mothers who are addicts or receiving treatment. In general terms, schools and educational institutes must become aware of possible positive outcomes (i.e., cognitive), and endogenous and exogenous problems of COAM, such that they can run drug specific awareness programs. In specific terms, schools must extend to include the implications of maternal addictions, so that teachers become aware of the complexities of problems around drug addictions and schools as places of education should be able to address these issues in positive ways and recognize (and not further stigmatize) implications at various levels of child development. In addition, specialist staff in schools such as Guidance Officers and School Psychologists and Support Staff should work together to develop multi-agency teams to support COAM. A long term study following COAM is much needed in terms of exploring how best to support COAM, what works or has worked, as addiction seem to lead to and/or appears to be associated with different sets of problems. However, caution must be exercised in generalizing these findings, as this study was archival in nature and thus etiology of problems could not be verified or assessed, and further data about problems could not be tested or validated with regard to the nature or the severity of the problems. However, the current study makes an important contribution in systematically documenting the problems of COAM.

\section{References}

1. Cicchetti D, Rizley R (1981) Developmental perspective on the etiology. Intergenerational transmission and sequelae of child abuse and neglect. Journal of American Academy of Child Adolescent Psychiatry 34: 541-565.

2. Ornoy A, Michailevskaya V, Lukashov I, Bar-Hamburger R, Harel S (1996) The developmental outcome of children born to heroin-dependent mothers, raised at home or adopted. Child Abuse Negl 20: 385-396. [Crossref]

3. Schempf AH (2007) Illicit drug use and neonatal outcomes: a critical review. Obstet Gynecol Surv 62: 749-757. [Crossref]

4. Wahlsten, VS, Sarman, I (2013) Neurobehavioral development of preschoolage children born to addicted mothers given opiate maintenance treatment with buprenorphine during pregnancy. Acta Paediatr 102: 544-549. [Crossref]

5. Dunn MG, Tarter RE, Mezzich AC, Vanyukov M, Kirisci L, et al. (2002) Origins and consequences of child neglect in substance abuse families. Clin Psychol Rev 22: 1063 1090. [Crossref]

6. Grekin ER, Brennan PA, Hammen C (2005) Parental alcohol use disorders and child delinquency: The mediating effects of executive functioning and chronic family stress. J Stud Alcohol 66: 14-22. [Crossref]

7. Conners NA, Bradley RH, Mansell LW, Liu JY, Roberts TJ, et al. (2003) Children of mothers with serious substance abuse problems: An accumulation of risks. Am J Drug Alcohol Abuse 29: 743-758. [Crossref]

8. Gruenert S (2004) The nobody's client project: Identifying and addressing the needs of children with substance dependent parents. Odyssey Institute of Studies.

9. Lambie G, Sias S (2005) Children of alcoholics: Implications for professional school counselors. Professional School Counselling 8: 266-273.

10. Lussier K, Laventure M, Bertrand K (2010) Parenting and maternal substance addiction: Factors affecting utilization of child protective service. Subst Use Misuse 45: 1572-1588. [Crossref]

11. Meredith V, Price-Robertson R (2011) Alcohol misuse and child maltreatment. National Child Protection Clearinghouse [NCPC], Resource Sheet, Melbourne, VIC: Australian Institute of Family Studies.

12. Capaldi L (2008) The relationship between parental substance abuse and the effects on young children. [Retrieved from http://digitalcommons.providence.edu/socialwrk students/1]

13. Dawe S, Frye S, Best D, Lynch M, Atkinson J, et al. (2007) Drug use in the family: Impacts and implications for children. Canberra, ACT: Australian National Council on Drugs.

14. Bancroft A, Wilson S (2007) The risk gradient in policy on children of drug and alcoho users: Framing young people as risky. Health, Risk \& Society 9: 311-322.

15. Hser YI, Evans E, Li L, Metchik-Gaddis A, Messina N (2014) Children of treated substance-abusing mothers. Clin Child Psychol Psychiatry 19: 217-232. [Crossref]

16. Pauz'e R, Toupin J, D'ery M, Mercier H, Joly J, et al. (2004) Portrait des jeunes `ag'es de 0 'a 17 ans r'ef'er'es 'a la prise en charge des centres jeunesse du Qu'ebec, leur parcours dans les services et leur 'evolution dans le temps. Groupe de recherche sur les inadaptations sociales de l'enfance: Universit'e de Sherbrooke.

17. Burke S, Schmied V, Montrose M (2006) Literature review: Parental alcohol misuse and the impact on children. Sydney, NSW: Department of Community Services.

18. Dawe S, Harnett P, Frye S (2008) Improving outcomes for children living in families with parental substance misuse: What do we know and what should we do. National Child Protection Clearinghouse [NCPC] Issue No. 29, Melbourne, VIC: Australian Institute of Family Studies.

19. Department of Child Safety (DCS) (2007) Parental substance misuse and child protection: Overview, indicators, impacts, risk and protective factors. Brisbane, Queensland: Queensland Government.

20. Johnson JL, Leff M (1999) Children of substance abusers: overview of research findings. Pediatrics 103: 1085-1099. [Crossref] 
21. O'Leary C (2007) Fetal alcohol syndrome: A literature review. Canberra, ACT: National Expert Advisory Committee on Alcohol.

22. Oei JL, Kingsbury A, Dhawan A, Burns L, Feller JM, et al. (2012) Amphetamines, the pregnant woman and her children: a review. J Perinatol 32: 737-747. [Crossref]

23. Brook JS, Balka EB, Crossman AM, Dermatis H, Galanter M, et al. (2010) The relationship between parental alcohol use, early and late adolescent alcohol use, and young adult psychological symptoms. Am J Addict 19: 534-542. [Crossref]

24. Kroll B, Taylor A, Aldgate J (2003) Parental substance misuse and child welfare. London: Jessica.

25. NSW Department of Community Services (2006) Parental alcohol misuse and the impact on children. [http://www.community.nsw.gov.au/docswr/assets/main/ documents/researchnotes_alcohol_misuse.pdf]

26. Ministerial Council on Drug Strategy (2001) Alcohol in Australia: Issues and strategies: A background paper to the National Alcohol Strategy. Canberra, ACT: Commonwealth of Australia.

27. Alati R, Baker P, Betts KS, Connor JP, Little K, et al. (2014) The role of parental alcohol use, parental discipline and antisocial behaviour on adolescent drinking trajectories. Drug Alcohol Depend 134: 178-184. [Crossref]

28. Walsh C, MacMillan HL, Jamieson E (2003) The relationship between parental substance abuse and child maltreatment: Findings from the Ontario Health Supplement. Child Abuse Negl 27: 1409-1425. [Crossref]

29. West MO, Prinz RJ (1987) Parental alcoholism and childhood psychopathology. Psychol Bull 102: 204-218. [Crossref]
30. Bada HS, Das A, Bauer CR, Shankaran S, Lester BM, et al. (2005). Low birth weight and preterm births: Etiologic fraction attributable to prenatal drug exposure. J Perinat 25: 631-637. [Crossref]

31. Oei J, Abdel-Latif ME, Clark R, Craig F, Lui K (2010) Short-term outcomes of mothers and infants exposed to antenatal amphetamines. Arch Dis Child Fetal Neonatal Ed 95: F36-41. [Crossref]

32. Ornoy A1, Segal J, Bar-Hamburger R, Greenbaum C (2007) Developmental outcome of school-age children born to mothers with heroin dependency: Importance of environmental factors. Dev Med Child Neurol 43: 668-675. [Crossref]

33. Linares TJ, Singer LT, Kirchner HL, Short EJ, Min MO, et al. (2006). Mental health outcomes of cocaine-exposed children at 6 years of age. J Paediatr Psychol 31: 85-97. [Crossref]

34. Peterson CC (2013) Looking forward through the lifespan: Developmental psychology Victoria, Australia: Pearson Australia.

35. Australian Institute of Health and Welfare (AIHW) (2013) National drug strategy household survey: Detailed findings. Drug statistics. Series no. 25. Cat. no. PHE 145. Canberra, ACT: Author.

36. Diagnostic Statistical Manual for Mental Disorders (DSM) IV (1994) Washington, DC American Psychological Association.

37. Diagnostic Statistical Manual for Mental Disorders (DSM) V (2015) Washington, DC: American Psychological Association.

38. WebMD (2005-2015) Enuresis and encopresis. [http://www.webmd.com/mentalhealth/elimination-disorders-encopresis]

Copyright: $\mathbb{0} 2017$ Lombard S, J-F. This is an open-access article distributed under the terms of the Creative Commons Attribution License, which permits unrestricted use, distribution, and reproduction in any medium, provided the original author and source are credited. 